Review

\title{
Mercury Exposure and Heart Diseases
}

\author{
Giuseppe Genchi ${ }^{1}$, Maria Stefania Sinicropi ${ }^{1, *}$, Alessia Carocci ${ }^{2, *}$, Graziantonio Lauria ${ }^{1}$ \\ and Alessia Catalano ${ }^{2}$
}

1 Dipartimento di Farmacia e Scienze della Salute e della Nutrizione, Università della Calabria, 87036 Arcavacata di Rende (Cosenza), Italy; giuseppe.genchi@unical.it (G.G.); glauria@unical.it (G.L.)

2 Dipartimento di Farmacia-Scienze del Farmaco, Università degli Studi di Bari “A. Moro”, 70125 Bari, Italy; alessia.catalano@uniba.it

* Correspondence: s.sinicropi@unical.it (M.S.S.); alessia.carocci@uniba.it (A.C.); Tel.: +39-0984-493200 (M.S.S.); +39-080-544-2745 (A.C.)

\begin{abstract}
Environmental contamination has exposed humans to various metal agents, including mercury. It has been determined that mercury is not only harmful to the health of vulnerable populations such as pregnant women and children, but is also toxic to ordinary adults in various ways. For many years, mercury was used in a wide variety of human activities. Nowadays, the exposure to this metal from both natural and artificial sources is significantly increasing. Recent studies suggest that chronic exposure, even to low concentration levels of mercury, can cause cardiovascular, reproductive and developmental toxicity, neurotoxicity, nephrotoxicity, immunotoxicity, and carcinogenicity. Possible biological effects of mercury, including the relationship between mercury toxicity and diseases of the cardiovascular system, such as hypertension, coronary heart disease and myocardial infarction, are being studied. As heart rhythm and function are under autonomic nervous system control, it has been hypothesized that the neurotoxic effects of mercury might also impact cardiac autonomic function. Mercury exposure could have a long-lasting effect on cardiac parasympathetic activity and some evidence show that mercury exposure might affect heart rate variability, particularly early exposures in children. The mechanism by which mercury produces toxic effects on the cardiovascular system is not fully elucidated, but this mechanism is believed to involve an increase in oxidative stress. The exposure to mercury increases the production of free radicals, potentially because of the role of mercury in the Fenton reaction and a reduction in the activity of antioxidant enzymes, such as glutathione peroxidase. In this review we report an overview on the toxicity of mercury and focus our attention on the toxic effects on the cardiovascular system.
\end{abstract}

Keywords: mercury; antioxidants; cardiovascular diseases; cardiotoxicity; chelating agents 


\section{Introduction}

20000-30000 years BC, Paleolithic artists used various pigments, including cinnabar (mercuric sulfide, $\mathrm{HgS}$ ) due to its red color, to draw hunting scenes with bison, bulls, stags, horses, humans and handprints in negative images on cave walls (Altamira-Spain and Lascaux-France caves). Even the Chinese and the Romans (VII-VI century BC) employed cinnabar for pictorial art. Subsequently, mercury has been used in thermometers, sphygmomanometers, barometers, incandescent lights, and batteries; moreover, it was employed in dental amalgams (typically composed of 50\% mercury, $25 \%$ silver and $25 \%$ tin, copper and nickel) [1], germicidal soaps and skin creams [2]. Mercury has also been used to purify gold and silver minerals by forming amalgams in Brazil basin, in Laos and in Venezuela mines. For a long time many medicines, cosmetics and vaccines contained small amounts of organic mercury compounds, like ethylmercury thiosalicylate (thimerosal), as preservatives. Medicinal uses of mercury have included its use as a diuretic, antiseptic, skin ointment, laxative, and as a treatment of syphilis. Mercury has also been used as a poison. The great sculptor Benvenuto Cellini, when poisoned by a sublethal dose of mercury, was apparently cured of a severe case of syphilis [3]. History has left us a lot of information on the effect of mercury toxicity. The earliest recorded death by mercury is the Chinese Emperor Qin Shi Huang (260-210 BC). According to legend, the cause of death most likely was mercury poisoning, due to his immortality treatments [4].

Certainly, the exposure to mercury brought harmful effect to health of humans and called the attention of the scientific world after the epidemics occurred in Japan and in Iraq. In Japan two methylmercury poisoning events are worthy of mention. These accidents, resulting from the deposition of industrial waste containing large quantities of methylmercury [5,6], occurred in the Japanese village of Minamata Bay (1953) and along the Agano river in Niigata (1964). Mercury, bioaccumulated within the food chain from plankton, microorganisms up to shellfish and fish, was then ingested, thus the inhabitants of Minamata Bay began to exhibit symptoms of neurological illness, i.e. uncontrollable trembling, loss of motor control, speech impairment, sensory disturbance, blindness, mental retardation, coma and death. Infants, whose mothers were infected, developed mental retardation, peripheral neuropathy and cerebral palsy. Nevertheless, in 1971 in rural Iraq, severe methylmercury intoxication occurred when bread was prepared and eaten from wheat seeds that had been treated with fungicides containing organic mercury compounds [6,7]. The Japan and Iraq incidents produced not only deaths, but also multiple and long-lasting intoxication symptoms, including blindness, deafness, mental retardation, cerebral palsy and dysarthria especially in children exposed in utero [8].

Methylmercury, the most toxic mercury compound, is an organic mercurial compound primarily found as a pollutant in rivers, lakes and oceans. Methylmercury is usually formed naturally through biomethylation of mercury, carried out by aquatic anaerobic sulfate-reducing bacteria [9,10] (Figure 1). It also derives from anthropogenic sources, and when formed will be released into rivers, lakes and oceans. Consequently, people whose diet consists mainly of shellfish and fish may be exposed to high levels of methylmercury [11]. Approximately $85 \%$ of 
methylmercury ingested is absorbed in the gastrointestinal tract, while about $5 \%$ is present in blood and $10 \%$ in brain. In many developing countries, mercury is still a major problem which requires actions for proper control. Many efforts should be placed on removal of anthropogenic sources of mercury and prevention of exposure.

\section{Chemical forms and toxicity of mercury}

Mercury ( $\mathrm{Hg}$, hydrargyrium from the Latin "liquid silver") is a heavy metal (atomic number 80 ; atomic weight 200.59 ; density $13.59 \mathrm{~g} / \mathrm{cm}^{3}$; melting point $-39{ }^{\circ} \mathrm{C}$; boiling point $359{ }^{\circ} \mathrm{C}$ ) of wellknown toxicity (World Health Organization 2007) [12] as lead and cadmium [13,14]. Mercury is a non-transition metal and is an extremely rare element in the Earth crust, usually in the form of the mineral cinnabar (mercury sulfide, $\mathrm{HgS}$ ), having an average mass abundance of only $0.09 \mathrm{mg} / \mathrm{Kg}$ [15]. Mercury has three valence states and exists in several forms: inorganic mercury, which includes liquid metallic mercury and mercury vapor $\left(\mathrm{Hg}^{0}\right)$, mercurous $\left(\mathrm{Hg}^{+}\right)$and mercuric $\left(\mathrm{Hg}^{++}\right)$ salts, and organic mercury, with methylmercury $\left(\mathrm{CH}_{3} \mathrm{Hg}, \mathrm{MeHg}\right)$, ethylmercury $\left(\mathrm{C}_{2} \mathrm{H}_{5} \mathrm{Hg}, \mathrm{EtHg}\right)$, and phenylmercury $\left(\mathrm{C}_{6} \mathrm{H}_{5} \mathrm{Hg}, \mathrm{PhHg}\right)$. The biological behavior and clinical significance of the various forms of mercury vary according to its chemical structure [16]. Elemental mercury $\left(\mathrm{Hg}^{0}\right)$, at room temperature, exists in its liquid form that quickly turns to vapor, when heated above room temperature. The high volatility of $\mathrm{Hg}^{0}$ prolongs the effects of anthropogenic release and $\mathrm{Hg}^{0}$ can remain suspended in the atmosphere for up to one year, where it can be transported and deposited globally. In the atmosphere, $\mathrm{Hg}^{0}$ constitutes the majority of mercury $(>90 \%)$ and is the predominant form in the gaseous phase, which facilitates the long-range transport of mercury at a global scale [17].

Mercury is released into the environment from both natural and anthropogenic sources. Annually, volcanic (for example Etna and Stromboli, Sicily, Italy), geothermal outgassing activities (for example the Phlegrean Fields, Pozzuoli, Italy), thermal springs, earthquakes, erosion and the volatilization of mercury present in the marine environment (Agency for Toxic Substances and Disease Registry, ATSDR 1999) [18-20] release an estimated 1,500 $\mathrm{t}$ of mercury to the environment [21]. Anthropogenic release occurs from manifold industrial point sources, chlor-alkali plants [22] and coal-fired power plants [23] and is estimated to constitute 2,320 $\mathrm{t}$ of mercury emitted annually into the atmosphere [21]. $\mathrm{Hg}^{0}$ is oxidized in air to its inorganic forms $\left(\mathrm{Hg}^{+}\right.$and $\mathrm{Hg}^{++}$) and is released during rain events to be deposited in soil and into the waters of rivers, lakes and oceans. In its vapor form, metallic mercury is commonly absorbed through the respiratory tract, while poorly absorbed in gastrointestinal tract. Because of its soluble characteristics, elemental mercury is highly diffusible through cell membranes as well as the blood-brain and placental barriers to reach target organs. Once in the blood stream, $\mathrm{Hg}^{0}$ is easily oxidized in red blood cells and tissues into inorganic $\mathrm{Hg}^{+}$and $\mathrm{Hg}^{++}$in the presence of catalase and peroxidase. The inorganic forms, $\mathrm{Hg}^{+}$and $\mathrm{Hg}^{++}$, have low lipophilicity and thus a limited ability to cross cell membranes. The mercuric form $\left(\mathrm{Hg}^{++}\right)$in the bloodstream binds to cysteine sulfhydryl groups (-SH) on erythrocytes, glutathione and metallothioneines or is transported suspended in plasma [24]. It is mainly absorbed 
through the respiratory tract, and in small extent through the skin (5-8\%) and gastrointestinal tract (3-5\%) (Figure 1).

The main excretory pathways include the urine and feces with a half-life of about two months. In aquatic and soil environments, mercury is primarily present in its mercuric form, including inorganic (e.g., mercuric hydroxide) and organic mercuric compounds, and secondarily as $\mathrm{Hg}^{0}$ [25,26]. Mercuric compounds can be found in different states, as mercuric chloride $\left(\mathrm{HgCl}_{2}\right.$, highly toxic and corrosive), mercuric sulfide ( $\mathrm{HgS}$, used as a pigment in paints), and mercury fulminate $\left(\left[\mathrm{Hg}(\mathrm{CNO})_{2}\right]\right.$, used as an explosive detonator). Mercuric mercury in the blood stream binds to -SH groups on erythrocytes, glutathione and metallothioneines or is transported suspended in plasma. There are experimental evidences that this compound is accumulated in the brain through its binding to cysteines [27]. Inorganic mercury, that derives from industrial release, is biomethylated to methylmercury $(\mathrm{MeHg})$, primarily by sulfate-reducing bacteria $[9,10,28]$, Although only a minor fraction of total mercury is present as $\mathrm{MeHg}$ (typically less than $10 \%$ and $3 \%$ in water and soil/sediment, respectively), the formation of this compound is an important step in mercury cycling. $\mathrm{MeHg}$ is easily absorbed overall into gastrointestinal tract (Figure 1) and is excreted in the feces, and less in urine.

Organic mercury crosses the blood-brain and the placental barriers and can be transmitted to fetus and, through breast milk, babies can assimilate these toxic compounds and bioaccumulated especially by the liver, brain, kidney and muscle [9]. MeHg bioaccumulate in the food chain from small creatures to larger predatory fish (i.e., swordfish, shark, king mackerel, tilefish) and sea mammals and reach high concentrations in organisms, in particular in aquatic environments [25]. Large predatory fish and sea mammals can contain methylmercury amount as much as 100000 times higher than the surrounding water medium. Consequently, population with high dietary intake of seafood should be subjected to exposure to high levels of mercury that has been reported to harm brain, lungs, kidneys, the nervous and immune systems and also heart and cardiovascular system [29]. Nevertheless, seafood and fish represent an important and great source of proteins especially for those populations living near the seas, lakes and rivers. Indeed, fish and shellfish contain proteins, as well as long-chain omega-3 polyunsaturated fatty acids (PUFA), including eicosapentaenoic acid (EPA) and docosahexaenoic acid (DHA) (Figure 2), and trace elements as selenium, calcium and magnesium [30]. The presence of mercury was detected in a wide variety of foods including dairy products as pasta, eggs, meats, poultry and vegetables. However, the level of mercury in these foods is very low compared to the level found in fish.

Methylmercury may also result from methylation of inorganic mercury by microorganisms in mouth, when mercury vapor is released from amalgam dental filling [31], and from nonenzymatic methylation, when Vit B12 in the form of methylcobalamin donates a methyl group to mercury [32]. The different mercury forms are interconvertible in vivo; for example, inhaled elemental mercury vapor is absorbed through mucous membrane of the lungs and rapidly oxidized to other forms. The organic compounds of mercury have a higher solubility in lipids than the inorganic species, thus they diffuse more easily through the lipid bilayer of biological membranes, 
increasing their potential toxicity. Mercury absorbed in the body mainly accumulates in the kidneys and brain. The half-life of mercury in the body is about 70 days.

Mercury has no known physiological role in human metabolism; furthermore, the human body lacks effective mechanisms to excrete it [33]. Mercury is not actively excreted by the human body, and then during the life of human beings in the average weight of 70-75 kg accumulates in the body up to $13 \mathrm{mg}$ [34]. Mercury is the most dangerous of all heavy metals to which humans and wildlife can be exposed. Both $\mathrm{Hg}^{0}$ and $\mathrm{MeHg}$ are neurotoxic, whereas inorganic mercury salts are nephrotoxic [35]. Mercury links to numerous biological structures blocking their activity. Indeed it has a high affinity for sulfhydryl groups (-SH) of aminoacids, proteins, enzymes, and sulfurcontaining antioxidants such as $N$-acetylcysteine (NAC), $\alpha$-lipoic acid (ALA) and glutathione (GSH) (Figure 3). Glutathione provides about 30-40\% of the plasma antioxidant capacity, and is the most potent intracellular and mitochondrial antioxidant by protecting against oxidative stress, inflammation and cardiovascular diseases [33,34,36-39].

Indeed mercury induces oxidative stress and mitochondrial dysfunctions. The latter occur at the NADH (reduced nicotinamide adenine dinucleotide) level: ubiquinone oxidoreductase (complex I of the respiratory chain), cytochrome $\mathrm{C}$ and cytochrome oxidase (complex IV of the respiratory chain), by causing displacement of $\mathrm{Fe}^{2+}$ and $\mathrm{Cu}^{+}$, by determining depolarization and autoxidation of the inner mitochondrial membrane with reduction in ATP synthesis, depletion of glutathione and increased lipid peroxidation [40]. Physiologic consequences include increased hydrogen peroxide, depletion of mitochondrial glutathione, increased lipid peroxidation, oxidation of pyridine nucleotides $\mathrm{NAD}(\mathrm{P}) \mathrm{H}$ (nicotinamide adenine dinucleotide phosphate) and altered calcium homeostasis [40]. Mercury binds to metallothioneines, replacing zinc, copper and other trace metals, and competes for selenium, reducing the effectiveness of the metalloenzymes. In addition, the complex mercury-selenium reduces the availability of selenium into the formation of the glutathione peroxidase, enzyme that breaks hydrogen peroxide and other toxic products. Omega-3 polyunsaturated fatty acids of fish and selenium antagonize some of the adverse effect of this heavy metal [41-44].

\section{Cardiovascular effect of mercury}

For many years mercury toxic effects were associated mainly with the central nervous system, kidney and brain; however, mercury may also produce cardiotoxicity [45-49]. Halbach and coauthors [50] had reported that exposure to mercury compounds, caused by frequent consumption of fish by the population of Amazon basin (Brazil), has a strong correlation with increased arterial blood pressure. Long after, Fillion and collaborators [51] studied the correlation between mercury exposure and blood pressure in the Brazilian Amazon. Other studies [34,38,52,53] correlate toxic mercury exposure with increased risk of myocardial infarction, atherosclerosis, hypertension and coronary dysfunction.

Mercury levels in the hair are predictors of the levels of oxidized LDL (low-density lipoprotein) that are frequently found in atherosclerosis lesions and are associated with 
atherosclerosis disease and acute coronary insufficiency [34,38,54]. The toxic effects of mercury in all its forms has been demonstrated both in vitro, in animals and human beings. Exposure to mercury increases the production of free radicals, reactive oxygen species (ROS) and superoxide anions on account of Fenton reaction [55-60]. Mercury binds to thiol (-SH) containing molecules and binds to selenium, forming selenium-mercury complexes, reducing the glutathione peroxidase, catalase and superoxide dismutase activities due to the absence of selenium in the active site of these enzymes [57,58,60-62]. The increment of ROS and the reduction of antioxidant enzymes activity increase the risk of developing cardiovascular disease [63,64]. In addition, mercury increases LDL oxidation and destroys plasma membrane phospholipid integrity by externalization of phosphatidylserine $[34,56,65,66]$. Moreover, the translocation of phosphatidylserine from the inner to the outer mitochondrial membrane leaflet leads to a modification of mitochondrial membranes with loss of mitochondrial potential and the occurrence of apoptosis. As a consequence, mitochondrial functions are altered, mitochondrial permeability transition (MPT) occurring with reduction of membrane potential, oxidative phosphorylation and ATP production.

Another mechanism, responsible for mercury toxic effects on the cardiovascular system, is through the inactivation of the paraoxonase, an extracellular antioxidative enzyme related to HDL (high-density lipoprotein) [67,68]. The inactivation of paraoxonase causes dysfunctional HDL to reduce reverse cholesterol transport. This enzyme also plays an important role as an antioxidant of LDL, a process that is directly involved in the development of atherosclerosis and in the risk of acute myocardial infarction, cardiovascular disease, coronary heart disease and carotid artery stenosis [69]. Mercury, in mammals, activates phospholipase A2 contributing to develop several inflammatory diseases correlated with coronary artery disease, acute coronary syndrome and cerebral plaque rupture [70]. Phospholipase A2 catalyzes the hydrolysis of glicerophospholipids at the sn-2 position, producing lysophosphatidic and arachidonic acids. In addition, mercury induces the formation of arachidonic acid metabolites, such as prostaglandins, thromboxanes, leukotrienes and related compounds that all are considered to be mediators of the inflammatory response even with cardiovascular problems [71]. According to the study by Salonen et al. [34], the level of mercury in the hair and fish intake was positively associated with an increased risk of acute myocardial infarction, death from cardiovascular disease and coronary heart disease This association was due to the effect of lipid peroxidation catalyzed by mercury, that highly contaminated fish in that region.

In Finland, lakes and soil have a low content of selenium, thus Finnish people have low dietary intake of selenium. Mercury effects and selenium deficiency in Eastern Finland population have been related to myocardial infarction, coronary heart disease and cardiovascular death, lipid peroxidation and progression of carotid atherosclerosis [72,73]. Fish are rich of selenium, an essential dietary trace element that in human beings is an important component of numerous selenoproteins and selenoenzymes [74,75], and that plays an important role in several antioxidant defense systems, protecting both against cardiovascular diseases and toxic effects of mercury. Indeed, in a population with low selenium intake the toxic effects of mercury may be more 
pronounced because the metal forms an insoluble complex with selenium, thus reducing its bioavailability in several antioxidant systems (e.g. glutathione peroxidase). Many of the cardiovascular problems related to mercury and mercury compounds are reduced by intake of fish or fish oil, which contain omega-3 PUFA, and by the intake of selenium. Changes in most risk factors are generally evident within weeks as a consequence of fish intake and can result from altered cell membrane fluidity following incorporation of omega-3 PUFA into cell membrane phospholipids [76], as well as direct binding of omega-3 PUFA to cytosolic receptors that regulate gene transcription [77]. Considerable evidences indicate that consumption of fish reduces coronary heart disease mortality [78], the leading cause of death in developed and in most developing nations. Many cardiovascular problems related to mercury are mitigated by the concomitant intake of fish, which contains omega-3 PUFA, and by intake of selenium [32]. On the other hand, concerns about potential damage from exposure to mercury (present in some fish species) have modified the concept of the fish as model of healthy food.

\section{Mercury chelating agents}

In acute mercury intoxication, after metal absorption into the circulation, the elimination from the body, to avoid further distribution and penetration in tissues, should be envisaged in order to reduce more serious damage. Employing mercury chelating agents [79], inducing diuresis, modulating urinary $\mathrm{pH}$ for metal excretion, employing complexing agents to enhance fecal excretion for metals undergoing extensive enterohepatic circulation, and finally hemodialysis, may be employed. The applicability and efficacy of these techniques vary depending upon type, intensity and extent of exposure and conditions of the patient.

Chelating agents (Figure 4), that can be used for inorganic mercury poisoning $\left(\mathrm{Hg}^{0}\right.$ and $\mathrm{Hg}^{++}$) include: 2,3-dimercaptopropanol (British Anti Lewisite, BAL), D-penicillamine (DPCN), 2,3-dimercaptosuccinic acid (DMSA), monoisoamyl ester of DMSA (MiADMSA) and 2.3dimercapto-1-propanesulfonic acid (DMPS). These compounds are able to chelate and immobilize mercury, because they contain sulfhydryl groups (-SH). BAL is highly water-soluble and can be administered orally and intravenously. DPCN is a water soluble derivative of penicillin, and increases the excretion of mercury through the urine. This drug is used only for metallic and inorganic mercury poisoning, but it cannot to be used for organic mercury poisoning [80]. Contraindications for this agent include: thrombopenia, proteinuria, hematuresis and nephrotic syndrome. DMSA increases excretion of methylmercury and inorganic mercury and when this drug is administered orally, its absorption rate is about $20 \%$ differently from DMPS, whose absorption rate is about $40 \%$ when taken orally. DMPS is more stable of DMSA, and it is frequently administered intravenously with a half-life of about $20 \mathrm{hrs}$. DMPS, as DMSA, promotes the excretion of methylmercury and inorganic mercury in urine. The water soluble MiADMSA is a derivative of DMSA and is administered via oral and intraperitoneal route, although oral administration has been found better than intraperitoneal injection. The concomitant administration of DMSA and MiADMSA has given better results than DMSA or MiADMSA administrated alone. 
This allowed to reduce the amount of chelating agents, promoting better clinical recovery and minimizing side effects [79].

\section{Conclusions}

Mercury is among the most toxic heavy metal and has no known physiological role in human beings. History has left us a lot of news on the effect of mercury toxicity on the humans. The earliest recorded death caused by mercury is the one of Qin Shi Huang Emperor of China (260-210 BC). The existence of different intake pathways of mercury (air, water, food, vaccines, pharmaceuticals and cosmetics) accounts for its easy accessibility to humans. In particular, in populations whose diet is based mainly on fish consumption, the risk of mercury exposure is increased. In many developing countries, mercury is still a big problem. Efforts have to be made to reduce the global mercury use. Exposure to mercury and its compounds brought harmful effects to human health as documented by the monstrous disasters originated from industrial spills in Japan (Minamata Bay and Agano River) and the rural poisoning in Iraq from MeHg-based fungicide. Mercury has a high affinity for thiol and seleno groups that are present in aminoacids as cysteine and Se-cysteine, $\mathrm{N}$-acetylcysteine, lipoic acid, proteins and enzymes. Cysteine is a precursor for the biosynthesis of glutathione, which is among the most powerful intracellular antioxidants. Mercury and methylmercury induce mitochondrial dysfunction, lowers ATP synthesis, depletes glutathione and increases phospholipid, protein and DNA peroxidation. Selenium and fish, rich in omega-3 polyunsaturated fatty acids, antagonize mercury toxicity. The vascular effects of mercury include increase in oxidative stress and inflammation, reduction in oxidative defense, thrombosis and mitochondrial dysfunction, depolarization and autoxidation of the inner mitochondrial membrane. Another mechanism, involving mercury toxic effects on the cardiovascular system, is the inactivation of paraoxonase that causes dysfunctional HDL to reduce reverse cholesterol transport to liver. This enzyme plays an important role as an antioxidant of LDL, thus it is directly involved in atherosclerosis, myocardial infarction and cardiovascular disease. Mercury toxicity is indeed strongly correlated with hypertension, coronary heart disease, myocardial infarction, cardiac arrhythmias, carotid artery obstruction, cerebrovascular accident and generalized atherosclerosis. Although in populations that eat fish the risk of mercury exposure is increased, important evidences, from human experimental studies, indicate that even modest consumption of fish and seafood significantly reduces cardiac disease and death. Selenium and fish rich in omega-3 polyunsaturated fatty acids antagonize mercury toxicity. In any case it is necessary to elucidate the risks and benefits of fish consumption and balance the toxic effects of mercury with the benefits derived from omega3 polyunsaturated fatty acids consumption.

Acknowledgements The authors gratefully acknowledge the financial support provided by Ministero dell'Istruzione, dell'Università e della Ricerca (MIUR, Italy).

Conflict of interest: The authors declare that there are no conflicts of interest. 


\section{References}

1. Bergdahl, I.A.; Schütz, A.; Ahlqwist, M.; Bengtsson, C.; Lapidus, L.; Lissner, L.; Hulten, B. Methylmercury and inorganic mercury in serum-correlation to fish consumption and dental amalgam in a cohort of women born in 1922. Environ. Res. 1998, 77, $20-24$.

2. Swain, E.B.; Jakus, P.M.; Rice, G.; Lupi, F.; Maxson, P.A.; Pacyna, J.M.; Penn, A.; Spiegel, S.J.; Veiga, M.M. Socioeconomic consequences of mercury use and pollution. Ambio 2007, $36,45-61$.

3. Geelhard, G. The record of an early mercurial cure in the history of syphilis with a case history of a 29 year old white male Renaissance genius. Aust. N Z J Surg. 1978, 48, 589594.

4. Zhao, H.L.; Zhu, X.; Sui, Y. The short-lived Chinese emperors. J. Am. Geriatr. Soc. 2006, $54,1295-1296$.

5. Tsubaki, T.; Irukajama, K. Minamata disease. Methylmercury poisoning in Minamata and Niigata, Japan. In: Tsubaki T, Irukajama K (eds) Minamata disease. Methylmercury poisoning in Minamata and Niigata, Japan. Kodansha, Tokyo, 1997, pp 317.

6. Carocci, A.; Rovito, N.; Sinicropi, M.S.; Genchi, G. Mercury toxicity and neurodegenerative effects. Rev. Environ. Contam. Toxicol. 2014, 229, 1-18.

7. Bakir, F.; Damluji, S.F.; Amin-Zaki, L.; Murtadha, M.; Khalidi, A.; Al-Rawi, N.Y.; Tikriti, S.; Dahahir, H.I.; Clarkson, T.W.; Smith, J.C.; Doherty, R.A. Methylmercury poisoning in Iraq. Science 1973, 181, 230-241.

8. Guzzi, G.; La Porta, C.A. Molecular mechanism triggered by mercury. Toxicology 2008, $244,1-12$.

9. Compeau, G.C.; Bartha, R. Sulfate-reducing bacteria: principal methylators of mercury in anoxic estuarine sediment. Appl. Environ. Microbiol. 1985, 50, 498-502.

10. Morel, F.M.M.; Kraepiel, A.M.I.; Amyot, M. The chemical cycle and bioaccumulation of mercury. Annu. Rev. Ecol. Syst. 1998, 29, 543-566.

11. Carocci, A.; Catalano, A.; Lauria, G.; Sinicropi, M.S.; Genchi, G. "Mercury Toxicity in Foods: A Review." in Food Toxicology for CRC Press/Taylor \& Francis (In press). 
12. World Health Organization (2007) Exposure to mercury: a major public health concern, Preventing disease through healthy environment. World Health Organization, Geneva

13. Sinicropi, M.S.; Caruso, A.; Capasso, A.; Palladino, C.; Panno, A.; Saturnino, C. Heavy metals: toxicity and carcinogenicity. Pharmacologyonline 2010b, 2, 329-333.

14. Carocci, A.; Catalano, A.; Lauria, G.; Sinicropi, M.S.; Genchi, G. Lead toxicity, antioxidant defense and environment. Rev. Environ. Contam. Toxicol. 2016, 238, 45-67.

15. Sinicropi, M.S.; Amantea, D.; Caruso, A.; Saturnino, C. Chemical and biological properties of toxic metals and use of chelating agents for the pharmacological treatment of metal poisoning. Arch Toxicol. 2010, 84, 501-520.

16. Bernhoft, R.A. Mercury toxicity and treatment: a review of the literature. J. Environ. Public Health. 2012, Article ID 460508, 10 pages.

17. Pirrone, N.; Mahaffey, K.R. Dynamics of mercury pollution on regional and global scales: atmospheric processes and human exposures around the world. New York: Springer-Verlag, 2005, 748pp.

18. Agency for Toxic Substances and Disease Registry (ATSDR), Toxicological Profile for Mercury, ATSDR, Public Health Service, US Department of Health and Human Services, Washington, DC, USA, 1999, http://www.atsdr.cdc.gov/toxprofiles/tp46.pdf.

19. Davidson, P.W.; Myers, G.J.; Weiss, B.; Shamlaye, C.F.; Cox, C. Prenatal methyl mercury exposure from fish consumption and child development: a review of evidence and perspectives from the Seychelles Child Development Study. NeuroToxicology 2006, 27, 1106-1109.

20. Lindberg, S.; Bullock, R.; Ebinghaus, R.; Engstrom, D.; Feng, X.; Fitzgerald, W.; Pirrone, N.; Prestbo, E.; Seigneur, C. A synthesis of progress and uncertainties in attributing the sources of mercury in deposition. Ambio 2007, 36, 19-32.

21. Pirrone, N.; Cinnirella, S.; Feng, X.; Finkelman, R.B.; Friedli, H.R.; Leaner, J. Global mercury emissions to the atmosphere from anthropogenic and natural sources. Atmos. Chem. Phys. 2010, 10, 5951-5964. 
22. Biester, H.; Müller, G.; Schöler, H.F. Binding and mobility of mercury in soils contaminated by emissions from chlor-alkali plants. Sci. Total Environ. 2002, 284, 191-193.

23. Novoa-Munoz, J.C.; Pontevedra-Pombal, X.; Martinez-Cortizas, A.; Garcia-Rodeja Gayoso, E. Mercury accumulation in upland acid forest ecosystems nearby a coal fired power-plant in Southwest Europe (Galicia, NW Spain). Sci. Total Environ. 2008, 394, 303-312.

24. Ballatori, N.; Clarkson, T.W. Biliary secretion of glutathione and of glutathione-metal complexes. Fundam. Appl. Toxicol. 1985, 5, 816-831

25. Ullrich, S.M.; Tanton, T.W.; Abdrashitova, S.A. Mercury in the aquatic environment: A review of factors affecting methylation. Crit. Rev. Environ. Sci. Technol. 2001, 31, 241-293.

26. Fitzgerald, W.F.; Lamborg, C.H.; Hammerschmidt, C.R. Marine biogeochemical cycling of mercury. Chem. Rev. 2007, 107, 641-662.

27. Clarkson, T.W.; Vyas, J.B.; Ballatori, N. Mechanisms of mercury disposition in the body. Am. J. Ind. Med. 2007, 50, 757-764.

28. Clarkson, T.W.; Magos, L. The toxicology of mercury and its chemical compounds. Crit. Rev. Toxicol. 2006, 36, 609-662.

29. Dabeka, R.; McKenzie, A.D.; Forsyth, D.S.; Conacher, H.B. Survey of total mercury in some edible fish and shellfish species collected in Canada in 2002. Food Addit. Contam. 2004, 21, 434-440.

30. Tacon, A.G.J.; Metian, M. Fish matters: importance of aquatic foods in human nutrition and global food supply. Rev. Fish. Sci. 2013, 21, 22-38.

31. Guzzi, G.; Grandi, M.; Cattaneo, C.; Calza, S.; Minoia, C.; Ronchi, A.; Gatti, A.; Severi, G. Dental amalgam and mercury levels in autopsy tissues: food for thought. Am. J. Forensic Med. Pathol. 2006, 27, 42-45.

32. Bertilsson, L.; Neujahr, H.Y. Methylation of mercury compounds by methylcobalamin. Biochemistry 1971, 10, 2805-2808.

33. International Programme on Chemical Safety (IPCS) (1990) Methylmercury. Environmental Health Criteria 101. Geneva, Switzerland: World Health Organization 
34. Salonen, J.T.; Seppänen, K.; Nyyssönen, K.; Korpela, H.; Kauhanen, J.; Kantola, M.; Tuomilehto, J.; Esterbauer, H.; Tatzber, F.; Salonen, R. Intake of mercury from fish, lipid peroxidation, and the risk of myocardial infarction and coronary, cardiovascular, and any death in eastern Finnish men. Circulation 1995, 91, 645-655.

35. Magos, L.; Webb, M.; Clarkson, T.W. The interactions of selenium with cadmium and mercury. Crit. Rev. Toxicol. 1980, 8, 1-42.

36. Salonen, J.T.; Seppänen, K.; Lakka, T.A.; Salonen, R.; Kaplan, G.A. Mercury accumulation and accelerated progression of carotid atherosclerosis: a population based prospective 4-year follow-up study in men in eastern Finland. Atherosclerosis 2000, 148, 265-273.

37. Guallar, E.; Sanz-Gallardo, M.I.; van't Veer, P.; Bode, P.; Aro, A.; Gómez-Aracena, J.; Kark, J.D.; Riemersma, R.A.; Martín-Moreno, J.M.; Kok, F.J. Mercury, fish oils, and the risk of myocardial infarction. N. Engl. J. Med. 2002, 347, 1747-1754.

38. Yoshizawa, K.; Rimm, E.B.; Morris, J.S.; Spate, V.L.; Hsieh, C.C.; Spiegelman, D.; Stampfer, M.J.; Willett, W.C. Mercury and the risk of coronary heart disease in men. $N$. Engl. J. Med. 2002, 347, 1755-1760.

39. Clarkson, T.W.; Magos, L.; Myers, G.J. The toxicology of mercury - current exposures and clinical manifestations. N. Engl. J. Med. 2003, 349, 1731-1737.

40. Shenker, B.J.; Guo, T.L.; Shapiro, I.M. Low-level methylmercury exposure causes human T-cells to undergo apoptosis: evidence of mitochondrial dysfunction. Environ. Res. 1998, 77, 149-159.

41. Ganther, H.E.; Sunde, M.L. Effect of tuna fish and selenium on the toxicity of methylmercury: a progress report. J. Food Sci. 1974, 39, 1-5.

42. Stoewsand, G.S.; Bache, C.A.; Lisk, D.J. Dietary selenium protection of methylmercury intoxication of Japanese quail. Bull. Environ. Contam. Toxicol. 1974, 11, 152-156.

43. Sumino, K.; Yamamoto, R.; Kitamura, S.A. Role of selenium against methylmercury toxicity. Nature 1977, 268, 73-74. 
44. Seppänen, K.; Kantola, M.; Laatikainen, R.; Nyyssönen, K.; Valkonen, V.P.; Kaarlöpp, V.; Salonen, J.T. Effect of supplementation with organic selenium on mercury status as measured by mercury in pubic hair. J. Trace Elem. Med. Biol. 2000, 14, 84-89.

45. Su, J.Y.; Chen, W.J. The effects of methylmercury on isolated cardiac tissues. Am. J. Pathol. 1979, 95, 753-764.

46. Halbach, S.; Schonsteiner, G.; Vierling, W. The action of organic mercury compounds on the function of isolated mammalian heart muscle. Eur. J. Pharmacol. 1989, 167, 255-264.

47. Massaroni, L.; Oliveira, E.M.; Stefanon, I.; Vassallo, D.V. Effects of mercury on the mechanical and electrical activity of the Langendorff-perfused rat heart. Braz. J. Med. Biol. Res. 1992, 25, 861-864.

48. Oliveira, E.M.; Vassallo, D.V.; Sarkis, J.J.F.; Mill, J.G. Mercury effects on the contractile activity of isolated heart muscle. Toxicol. Appl. Pharmacol. 1994, 128, 86-91.

49. Hussain, S.; Rodgers, D.A.; Duhart, H.M.; Ali, S.F. Mercuric chloride-induced reactive oxygen species and its effect on antioxidant enzymes in different regions of rat brain. $J$. Environ. Sci. Health B. 1997, 32, 395-409.

50. Halbach, S. Mercury compounds: lipophilicity and toxic effects on isolated myocardial tissue. Arch. Toxicol. 1990, 64, 315-319.

51. Fillion, M.; Mergler, D.; Sousa Passos, C.J.; Larribe, F.; Lemire, M.; Guimarães, J.R.D. A preliminary study of mercury exposure and blood pressure in the Brazilian Amazon. Environ. Health 2006, 5, 29.

52. Bastos, W.R.; Gomes, J.P.O.; Oliveira, R.C.; Almeida, R.; Nascimento, E.L.; Bernardi, J.V.E.; Drude de Lacerda, L.; da Silveira, E.G.; Pfeiffer, W.C. Mercury in the environment and riverside population in the Madeira River Basin, Amazon, Brazil. Sci Total Environ. 2006, 368, 344-351.

53. Houston, M.C. The role of mercury and cadmium heavy metals in vascular disease, hypertension, coronary heart disease, and myocardial infarction. Altern. Ther. Health Med. 2007, 13, S128-S133. 
54. Virtanen, J.K.; Voutilainen, S.; Rissanen, T.H.; Mursu, J.; Tuomainen, T.P.; Korhonen, M.J.; Valkonen, V.P.; Seppänen, K.; Laukkanen, J.A.; Salonen, J.T. Mercury, fish oils, and risk of acute coronary events and cardiovascular disease, coronary heart disease, and allcause mortality in men in Eastern Finland. Arterioscler. Thromb. Vasc. Biol. 2005, 25, 228 233.

55. Miller, D.M.; Lund, B.O.; Woods, J.S. Reactivity of $\mathrm{Hg}(\mathrm{II})$ with superoxide: evidence for the catalytic dismutation of superoxide by $\mathrm{Hg}(\mathrm{II})$. J. Biochem. Toxicol. 1991, 6, 293-298.

56. Park, S.T.; Lim, K.T.; Chung, Y.T.; Kim, S.U. Methylmercury-induced neurotoxicity in cerebral neuron culture is blocked by antioxidants and NMDA receptor antagonists. Neurotoxicology 1996, 17, 37-45.

57. Clarkson, T.W. The toxicology of mercury. Crit. Rev. Clin. Lab. Sci. 1997, 34, 369-403.

58. Magos, L. Physiology and toxicology of mercury. Met. Ions Biol. Syst. 1997, 34, 321-370.

59. Ehara, S.; Ueda, M.; Naruko, T.; Haze, K.; Itoh, A.; Otsuka, M.; Komatsu, R.; Matsuo, T.; Itabe, H.; Takano, T.; Tsukamoto, Y.; Yoshiyama, M.; Takeuchi, K.; Yoshikawa, J.; Becker, A.E. Elevated levels of oxidized low density lipoprotein show a positive relationship with the severity of acute coronary syndromes. Circulation 2001, 103, 1955-1960.

60. Kobal, A.B.; Horvat, M.; Prezelj, M.; Briski, A.S.; Krsnik, M.; Dizdarevic, T.; Mazej, D.; Falnoga, I.; Stibilj, V.; Arneric, N.; Kobal, D.; Osredkar, J. The impact of long-term past exposure to elemental mercury on antioxidative capacity and lipid peroxidation in mercury miners. J. Trace Elem. Med. Biol. 2004, 17, 261-274.

61. Cuvin-Aralar, M.L.; Furness, R.W. Mercury and selenium interaction: a review. Ecotoxicol. Environ. Saf. 1991, 21, 348-364.

62. Farina, M.; Aschner, M.; Rocha, J.B.T. Oxidative stress in MeHg-induced neurotoxicity. Toxicol. Appl. Pharmacol. 2011, 256, 405-417.

63. Magos, L.; Clarkson, T.W. Overview of the clinical toxicity of mercury. Ann. Clin. Biochem. 2006, 43, 257-268.

64. Valko, M.; Rhodes, C.J.; Moncol, J.; Izakovic, M.; Mazur, M. Free radicals, metals and antioxidants in oxidative stress-induced cancer. Chem.-Biol. Interact. 2006, 160, 1-40. 
65. Lin, T.H.; Huang, Y.L.; Huang, S.F. Lipid peroxidation of rats administered with methyl mercuric chloride. Biol. Trace Elem. Res. 1996, 54, 33-41.

66. InSug, O.; Datar, S.; Koch, C.J.; Shapiro, I.M.; Shenker, B.J. Mercuric compounds inhibit human monocyte function by inducing apoptosis: evidence for formation of reactive oxygen species, development of mitochondrial membrane permeability transition and loss of reductive reserve. Toxicology 1997, 124, 211-224.

67. Gonzalvo, M.C.; Gil, F.; Hernandez, A.F.; Villanueva, E.; Pla, A. Inhibition of paraoxonase activity in human liver microsomes by exposure to EDTA, metals and mercurials. Chem. Biol. Interact. 1997, 105, 169-179.

68. Salonen, J.T.; Malin, R.; Tuomainen, T.P.; Nyyssönen, K.; Lakka, T.A.; Lehtimäki, T. Polymorphism in high density lipoprotein paraoxonase gene and risk of acute myocardial infarction in men: prospective nested case-control study. BMJ 1999, 319, 487-488.

69. Kulka, M. A review of paraoxonase 1 properties and diagnostic applications. Pol. J. Vet. Sci. 2016, 19, 225-232.

70. Mallat, Z.; Lambeau, G.; Tedgui, A. Lipoprotein-associated and secreted phospholipases $\mathrm{A}_{2}$ in cardiovascular disease: roles as biological effectors and biomarkers. Circulation 2010, $122,2183-2200$.

71. Houston, M.C. The role of mercury in cardiovascular disease. J. Cardiovasc. Dis. Diagn. 2014, $2,1-8$.

72. Salonen, J.T.; Alfthan, G.; Huttunen, J.K.; Pikkarainen, J.; Puska, P. Association between cardiovascular death and myocardial infarction and serum selenium in a matched-pair longitudinal study. Lancet 1982, 24, 175-179.

73. Salonen, J.T.; Ylä-Herttuala, S.; Yamamoto, R:; Butler, S.; Korpela, H.; Salonen, R.; Nyyssönen, K.; Palinski, W.; Witztum, J.L. Autoantibody against oxidized LDL and progression of carotid atherosclerosis. Lancet 1992, 339, 883-887.

74. Levander, O.A. A global view of human selenium nutrition. Annu. Rev. Nutr. 1987, 7, $227-$ 250.

75. Brown, K.M.; Arthur, J.R. Selenium, selenoproteins and human health: a review. Public Health Nutr. 2001, 4, 593-599. 
76. Clandinin, M.T.; Cheema, S.; Field, C.J.; Garg, M.L.; Venkatraman, J.; Clandinin, T.R. Dietary fat: exogenous determination of membrane structure and cell function. Faseb J. 1991, 5, 2761-2769.

77. Vanden Heuvel, J.P. Diet, fatty acids, and regulation of genes important for heart disease. Curr. Atheroscler. Rep. 2004, 6, 432-440.

78. Mozaffarian, D.; Rimm, E.B. Fish intake, contaminants, and human health: evaluating the risks and the benefits. JAMA 2006, 296, 1885-1899.

79. Flora, S.J.; Pachauri, V. Chelation in metal intoxication. Int. J. Environ. Res. Public Health 2010, 7, 2745-2788.

80. Ford, M.D.; Delaney, K.A.; Ling, L.J.; Erickson, T. Clinical toxicology. Philadelphia: W. B. Saunders Company; 2001.

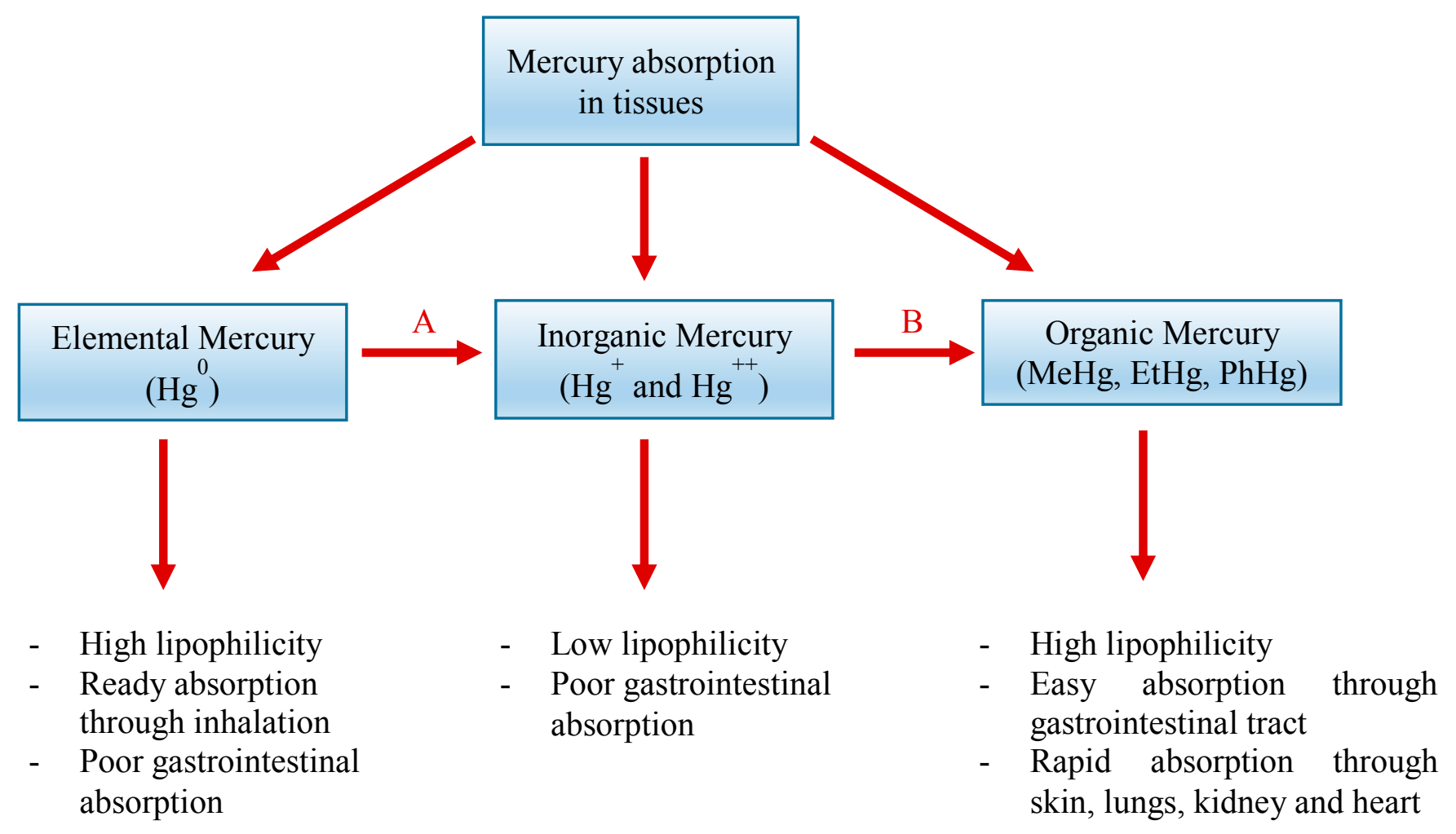

Figure 1. Bioavailabilty and toxic effects of mercury and its compounds.

(A) Oxidation in air, and enzymatically in red blood cells and tissues. (B) Biomethylation by sulfate-reducing bacteria. 

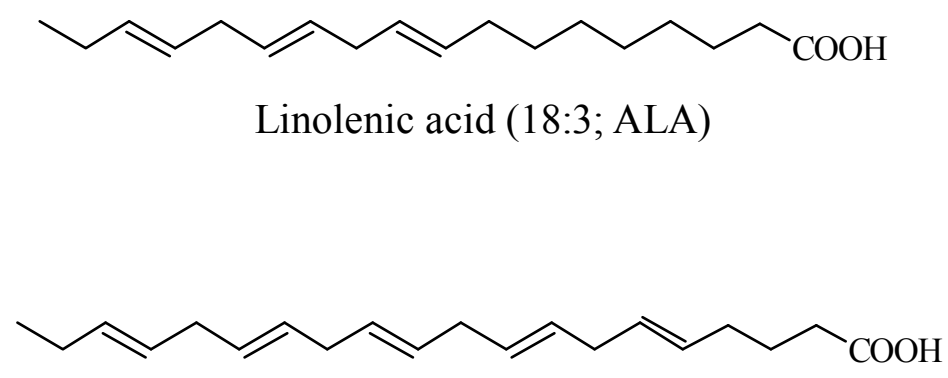

Eicosapentaenoic acid (20:5; EPA)

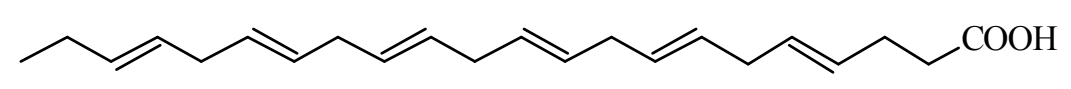

Docosahexaenoic acid (22:6; DHA)

Figure 2. Main fatty acids of the omega-3 PUFA group.<smiles>CC(=O)NC(CS)C(=O)O</smiles>

$\mathrm{N}$-acetylcysteine (NAC)<smiles>O=C(O)CCCCC1CCSS1</smiles>

$\alpha$-lipoic acid (ALA)<smiles>NC(CCC(=O)NC(CS)C(=O)NCC(=O)O)C(=O)O</smiles>

glutathione

(GSH)

Figure 3. Antioxidants such as $N$-acetylcysteine (NAC), $\alpha$-lipoic acid (ALA) and glutathione (GSH). 
<smiles>OCC(S)CS</smiles>

2,3-Dimercaptopropanol (British Anti Lewisite, BAL)<smiles>NC(C(=O)O)C(F)(F)S</smiles>

D-penicillamine (DPCN)<smiles>O=C(O)C(S)C(S)C(=O)O</smiles>

2,3-Dimercaptosuccinic acid

(DMSA)<smiles>CC(C)CCOC(=O)[C@H](S)C(S)C(=O)O</smiles>

Monoisoamyl ester of DMSA (MiADMSA)<smiles>O=S(=O)(O)CC(S)CS</smiles>

2,3-Dimercapto-1-propanesulfonic acid (DMPS)

Figure 4. Structures of common substrates chelating mercury.

(C) 2016 by the authors; licensee Preprints, Basel, Switzerland. This article is an open access article distributed under the terms and conditions of the Creative Commons by Attribution (CC-BY) license (http://creativecommons.org/licenses/by/4.0/). 